\title{
DISCURSOS SOBRE LAS PRÁCTICAS DEL GRAFFITI EN EL PERIÓDICO LA NACIÓN (2001-2010)
}

\section{DISCOURSES ABOUT GRAFFITI PRACTICES IN LA NACIÓN NEWSPAPER (2001-2010)}

\author{
Alexander Araya López*
}

RESUMEN

Este artículo presenta los principales discursos asociados a las prácticas del graffiti (tagging, arte urbano, político) y sus productores en el periódico La Nación, durante el periodo 2001-2010. A través del análisis cualitativo de artículos de noticia y de opinión, el graffiti aparece como una amenaza a nociones de patrimonio y bien común, enfatizando su impacto sobre el orden público y la seguridad. No obstante, el graffiti en su forma más artística (influenciado por la cultura hip-hop) parece ser aceptado socialmente solo a partir de la institucionalización de la práctica, considerando su valor estético y sus usos sociales.

PALABRAS CLAVE: GRAFFITI * JUVENTUD * PRENSA * CRIMINALIDAD JUVENIL * ANÁLISIS DEL DISCURSO

\section{ABSTRACT}

This article presents the main discourses associated to the practices of graffiti (tagging, street art, political) and its producers in the newspaper La Nación, during the period 2001-2010. Through the qualitative analysis of both news and opinion articles, the graffiti appears as a threat to notions of heritage and common good, emphasizing its impact in the public order and the security. However, the graffiti in its more artistic form (influenced by the hip-hop culture) seems tobesocially accepted only through the institutionalization of the practice, considering its a esthetic value and social uses.

KEYWORDS: GRAFFITI * YOUTH * PRESS * JUVENILE CRIMINALITY * DISCOURSE ANALYSIS

Escuela de Sociología, Universidad de Costa Rica (UCR).

alxaraya@gmail.com 


\section{INTRODUCCIÓN}

Este artículo presenta los principales discursos sobre prácticas del graffiti en el contexto costarricense, obtenidos a partir del análisis cualitativo de textos periodísticos y de opinión que fueron publicados entre 2001 y 2010 . La investigación tiene un corte exploratorio y descriptivo (Araya 2014). Los casos seleccionados para el estudio fueron el periódico La Nación (Costa Rica) y el Folha de São Paulo (Brasil). Este artículo hace escasa referencia al caso brasileño, dado que la investigación no es de corte comparativo. La muestra corresponde a 246 artículos, obtenidos a través de la palabra clave "graffiti", en la página web de La Nación ${ }^{2}$.

Esta investigación aborda el "graffiti" como un tema que no es exclusivo de la juventud (urbana), sino que incluye en su producción y consumo a ciertos sectores de la población adulta. La juventud, siguiendo una aproximación crítica al concepto, incluye individuos que están a favor de dicha práctica $y$ otros $u$ otras en contra ${ }^{3}$. Esta apreciación

$1 \quad$ La palabra clave "graffiti" ("grafiti")fue empleada para la selección de los artículos, incluyendo además las formas de los productores "grafitero" y "grafitera". Considerando posibles errores de ortografía, la búsqueda también fue realizada con el término "grafitti", con dos "t". El término pinta/pintada fue excluido de la búsqueda, dado que refiere a la conjugación y adjetivo del verbo pintar, lo que habría complicado el proceso de selección de la muestra.

2 La búsqueda fue realizada a partir del archivo de nación.com. Lamentablemente, esto reduce los resultados a aquellas noticias que fueron incluidas por el medio en su página web, sin que sean necesariamente las mismas noticias que fueron impresas. En caso de dudas, se eliminaron los artículos que parecían ser producidos solamente para consumo online (como la sección "Última hora"). Durante el proceso de investigación, La Nación alteró significativamente su página de internet, lo que podría generar dificultades para recuperar los artículos mencionados en el estudio.

3 Este artículo promueve el lenguaje inclusivo de género. Sin embargo, dado el anonimato de los productores de estas prácticas, es imposible saber el número de mujeres involucradas en la producción de graffiti. En ocasiones, se emplea el lenguaje en masculino para enfatizar que la práctica es percibida como "mayoritariamente" masculina. parte de una percepción amplia de la juventud, entendiéndola como diversa, compleja $y$ contradictoria; como una población que no puede ser reducida a criterios como "edad" o "comportamiento" (Valenzuela en MartínBarbero et ál. 2005; Musgrove 1964; Reguillo 2000 y Macassi 2001).

En este sentido, se hace referencia a las prácticas del graffiti para de-construir conceptualmente un término que es aplicado a una diversidad de fenómenos sociales. Desde inscripciones de corte político hasta arte urbana financiado por empresas locales o corporaciones son homogenizadas en el vocablo "graffiti". Esta investigación, además, se ha alejado de percepciones a priori de las y los grafiteros como "artistas" o "vándalos", prefiriendo el término más neutral de "productores". Es a partir de la revisión de literatura secundaria (Cruz 2008; Manco, Neelon y Art 2005; Kozak 2004; Austin 2001; Schlecht 1995; Ferrell 1993; Lachmann 1988; Silva 1986; Ley y Cybriwsky 1974) ${ }^{4}$ y de una primera observación de la información empírica que se ha propuesto una tipología de estas prácticas: a) Graffiti político: para referirse a las inscripciones o dibujos que tienen una intención o contenidos explícitamente políticos; b) Graffiti financiado o de marca: que consiste en formas de arte urbano, inscripciones o "murales" que son creados a partir de colaboraciones entre productores $y$ empresas o corporaciones, en ocasiones siendo una estrategia para capturar consumidores (juveniles); c) Graffiti en comisión u "oficial": creado en colaboración con instituciones

$4 \quad$ Dos estudios han sido recientemente producidos en Costa Rica en torno al tema del graffiti artístico. La investigación de Marialina Villegas (2009) sobre el graffiti (artístico) en el Edificio Saprissa (UCR) y en el barrio la California. Este estudio ofrece una visión de la práctica desde la perspectiva de sus productores y a través del uso de material fotográfico. El segundo estudio, realizado por Marvin Rodríguez (2014) se enfoca en una lectura sociológica del graffiti. Este no fue revisado ni para la investigación doctoral ni para la creación de este artículo, dado que no se encuentra accesible por vía digital. Agradezco al evaluador por sugerir la referencia a ambos trabajos. 
como gobiernos locales, universidades, ongs, museos, etc., frecuentemente ligados a una causa social; d) Arte urbano (Street art): siendo prácticas cuyo objetivo es la transformación estética del espacio urbano-rural, que no es apoyado por instituciones o empresas, siendo "no necesariamente" político, creado a partir de individuos o grupos que lo producen desde la legalidad o la "ilegalidad"; $y$ finalmente e) Graffiti territorial: constituyéndose en formas como las firmas (tagging), así como, otras inscripciones variadas creadas por "barras de fútbol", maras, pandillas, entre otros ${ }^{5}$.

La tipología propuesta permite entender "el" graffiti y otras formas de inscripciones en propiedades públicas y privadas más allá de la idea de "vandalismo" y "contracultura". Dado que algunas de estas producciones son realizadas dentro del ordenamiento jurídico (con la autorización escrita del propietario o con la colaboración de empresas e instituciones), el "graffiti" no sería necesariamente antagonista de ideologías dominantes, ni se puede etiquetar como ajeno a dinámicas de producción y consumo capitalistas.

Los productores de estas prácticas también responden a motivaciones que no pueden ser generalizadas. En algunos casos, el graffiti (tagging culture) se orienta a la búsqueda de adrenalina (Ferrell 1993 y 2004), asociada también a una economía de "prestigio" (Austin 2001). Otras motivaciones pueden ser políticas, estéticas o emotivas-afectivas, dependiendo de quiénes son los productores y del contexto en que son creadas. Sin embargo, es importante mencionar, que esto no permite considerar a las y los productores de graffiti como "inferiores", "poco educados", que están "carentes de espacios de expresión"; sino que por el contrario, se les puede entender como una forma de público subalterno (Habermas 1990; Fraser 1990; Avritzer y Costa 2004). Si bien, una firma anónima en un monumento público puede ser interpretada como una "falta de educación", otra lectura posible es entender ese mismo

$5 \quad$ Otras formas de graffiti que podrían incluirse en esta categorización es el graffiti personal, la latrinalia (graffiti e inscripciones en sanitarios públicos), el graffiti carcelario, entre otros. acto como un rechazo a una historia oficial y (pseudo)-compartida que nos representaría a todas $y$ todos.

El análisis del discurso empleado en la investigación ha prestado atención no solamente a los artículos de opinión y de noticias publicados, sino que además ha considerado los contextos históricos, sociales y cognitivos en que dichos textos fueron producidos (van Dijk 1988a y 1988b). Con base en una interpretación cualitativa del discurso basada en la metodología propuesta por Tonkiss $(2004,378)$, tres grandes tareas fueron efectuadas en este ejercicio de seguir el discurso ("tracking discourse", según Altheide (1997, 659)): a) La identificación de temas centrales, b) la búsqueda de variación en el tiempo y c) la identificación de silencios, en el sentido de temas no abordados por el medio de comunicación ${ }^{6}$.

Es importante mencionar que como señala Bell (2011), los resultados de este tipo de estudios no pueden ser calificados como la única interpretación posible de los textos analizados. A partir de una perspectiva de corte hermenéutico, se han considerado lecturas alternativas, polisemias, así como, el distanciamiento (Verfremdung) del texto por parte del investigador. En este sentido, otras lecturas, conexiones e interpretaciones pueden ser posibles $y$ esperables a partir de la "misma" información empírica, sin que esto necesariamente signifique que una interpretación tiene mayor o menor valía. Además, este trabajo ha abordado la prensa desde una perspectiva dialógica, entendiendo La Nación como un canal donde diversos actores sociales pueden contribuir al debate del tema.

$6 \quad$ Una serie de categorías fue creada a partir de la revisión de literatura y los textos fueron categorizados en ATLAS.ti. Entre las categorías se incluye: criminogénico, protesta, arte, post-graffiti, comisionado, tags, subcultura, anti-graffiti, entre otras. El capítulo metodológico del estudio (en inglés) y datos empíricos puede ser solicitados al autor. 


\section{DE LA ESFERA PÚBLICA AL ESPACIO PÚBLICO Y VICEVERSA}

Para comprender los discursos acerca de las prácticas de graffiti en las sociedades contemporáneas y particularmente, en la sociedad costarricense, es necesario hacer referencia a una serie de fundamentaciones $y$ debates teóricos que se relacionan en mayor o menor medida con el tema.

Primero, tal como he mencionado anteriormente, la "juventud urbana" ha sido reducida $y$ homogenizada en términos etarios $y$ de comportamiento, ignorando las diversas manifestaciones $y$ formas contradictorias de "ser joven" (Reguillo 2000). Existen, además, tres grandes enfoques del tema de la juventud (Macassi 2001). El primer paradigma refiere al tema de la "violencia social" y se relaciona con el papel de los jóvenes en la reproducción de la violencia, ya sea a partir de criterios como tasas de homicidio, inserción en pandillas, entre otros. El enfoque de "moratoria social" remite a indicadores relacionados con factores económicos y educativos, tasas de desempleo y subempleo, entre otros. La tercera visión - con autores como Reguillo (2000) y Valenzuela, citado en Martín-Barbero et ál. 2005) - destaca el tema de las "culturas juveniles", es decir, las diversidad de morales, lenguajes, cotidianidades $y$ formas de experimentar la(s) juventud(es).

Es a partir de una combinación de estos enfoques que se ha cuestionado la validez de una categoría única de graffiti, así como, la "homogeneidad" de sus productores. No obstante, la juventud se ha interpretado en esta investigación como un sector poblacional en dependencia, afectado por las decisiones que son tomadas por el sector "adulto" de la población. Es por esta razón que, basado en el concepto de esfera pública propuesto por Habermas (1990) y considerando los aportes de Fraser (1990) y Avritzer y Costa (2004), "la" juventud se ha considerado como un sector subalterno (o incluso "contracultural" o "diaspórico"7), que intenta hacer validar sus

$7 \quad$ Esta idea de públicos diaspóricos refiere a grupos cuyas formas de expresión van más allá de la palabra escrita y/o hablada (o la retórica), para incluir otras formas alternativas de expresión política, según la interpretación de Gilroy hecha por Avritzer y Costa $(2004,11)$. derechos y ser reconocido en los procesos de formación de opinión y toma de decisiones.

"La" juventud, como se ha mencionado en relación con el enfoque de violencia social, ha sido y quizás aún hoy es considerada como una población prioritaria en temas de criminalidad, no solo por su rol como reproductor de la violencia sino por "estar en riesgo" de insertarse en organizaciones criminales $y$ delictivas. Los discursos sobre la juventud han incluido estas formas de estigmatización (Goffman 1963) y de pánicos morales (Cohen 2002), que han funcionado como mecanismos de control social. Mientras algunas prácticas juveniles han sido relativamente bien recibidas, otras prácticas atribuidas a los jóvenes son consideradas como desviadas, improductivas, irracionales, de riesgo, etc. Es a partir de un verstehen criminológico, indica Ferrell (1999), que se puede observar el entrelazamiento de la emergencia de discursos sobre prácticas culturales y su designación como "crímenes". Algunos de estos discursos son rechazados y cuestionados por los y las jóvenes, a través del uso de nuevas/alternativas tecnologías de comunicación (McRobbie y Thornton 1995) en un ejercicio de "pluralismo contencioso" (Guidry y Sawyer 2003). Otras de estas etiquetas son por el contrario adoptadas por "la" juventud y convertidas en símbolos de estatus, con la propia divulgación y celebración de su "actividad criminal" (ver el caso de la pichação en Araya 2013, 296-297 y Yar 2012).

El modelo ortodoxo de la criminología de las "Ventanas Rotas"8 (Wilson y Kelling 1982) es un ejemplo paradigmático de esta tendencia de criminalización y sospecha. No solamente los jóvenes sino que también poblaciones en mendicidad o trabajadores sexuales son considerados como "ventanas rotas", como señales de un espacio social en decadencia. Según los fundadores de este modelo, la tolerancia cero de estos crímenes menores y del "comportamiento antisocial" evitaría la generación de otros

$8 \quad$ Este enfoque es particularmente importante para comprender los discursos del graffiti en los artículos de opinión de La Nación. 
crímenes más serios (que resultarían de la percepción generalizada de un espacio social que se encuentra a la deriva y que nadie se interesa).

Sin embargo, tal como señalan los críticos a este modelo, esto no significa necesariamente que la actividad en cuestión (por ejemplo, el graffiti, el consumo de drogas o la prostitución) sea necesariamente ilegal o reprochable, sino que enfatiza el "desorden" que dicha práctica genera en el espacio público. Así, grupos que tienen los recursos y privilegios para minimizar la exposición de su desorden, se beneficiarían al no ser víctimas de estas campañas de estigmatización o al no ser castigados jurídicamente por sus "comportamientos desviados" (Sampson y Raudenbush 2004; a partir de Stinchcombe 1963). La idea de pureza (Duschinsky 2013), necesaria para entender enfoques epidemiológicos, parece estar asociada a esta percepción del desorden.

Esta preocupación con el desorden y con la seguridad es observable en la emergencia de espacios diseñados para la prevención de la criminalidad (сттеD), que se ha convertido en una tendencia de los espacios urbanos contemporáneos (Kaytal 2002 y Zahm 2007). Al promover la "vigilancia natural" a través del uso de tecnologías de punta de control social como cámaras en circuito cerrado (cстv), estos nuevos espacios seguros pueden ser interpretados como nuevas formas de exclusión social; si bien los crímenes que se cometían en un área con cámaras pueden trasladarse geográficamente a un nuevo espacio sin cámaras (Welsh y Farrington 2003), estas tecnologías son también una mercancía accesible solamente a ciertos sectores económicamente privilegiados. En realidad, tal como señalan Goold, Loader y Thumala (2010), estas medidas de seguridad son consumidas por los ciudadanos de forma secundaria, generalmente como resultado de decisiones tomadas por otros (corporaciones, autoridades locales, etc.). Así, el

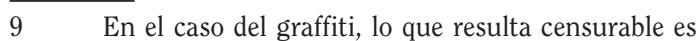
la apropiación del espacio público o privado, y no la escritura en la pared en sí. Cuando existen los permisos correspondientes, formas de graffiti de marca u "oficial" —así como formas de arte urbano- no atentan contra el ordenamiento jurídico (ni contra los intereses particulares de los propietarios). espacio seguro no solamente considera al individuo como una "víctima potencial" sino como una "amenaza potencial". Además, estas tecnologías inciden en forma desigual en aquellas poblaciones cuyos derechos ya se encuentran en un nivel diferenciado en comparación con el resto de la ciudadanía, tal como sucede con los jóvenes, poblaciones en mendicidad, trabajadores sexuales, migrantes ilegales, etc.

Esta desigualdad del acceso al espacio es el resultado de una "racionalidad espacial" que privilegia, como señala Harvey (2001, 81), la circulación de trabajadores y mercancías en las dinámicas de producción y consumo. Siguiendo la Sociología del espacio y de las ciudades propuestas por Löw (2001 y 2010), es necesario reconocer que ante estos espacios "capitalistas" se da la emergencia de espacios alternativos o de disidencia. Además, según Löw, es necesario pensar la espacialidad como una multiplicidad, superando visiones que limitan el espacio a un mero contenedor de cosas. Con base en el trabajo de Läpple (en Häußermannet. al. 1992), Löw entiende el espacio como una combinación de: a) el substrato físico-material, b) de condiciones de clase y poder ligadas a la interacción social, c) de regulaciones legales, estéticas y de propiedad en marco institucional y normativo, y d) del sistema de signos y símbolos. A este espacio múltiple, tanto Löw $(2010,79)^{10}$ como Thrift $(2005,138)^{11}$ agregan el nivel afectivoemotivo, el cual es generalmente subestimado en las lecturas más ortodoxas del espacio.

Esta racionalidad espacial no solamente es impuesta físicamente sino que se acompaña de proceso de control de las emociones, imponiendo una lógica basada en la distancia y en el silencio (Sennett, 1990 y 2002). El espacio público deja de ser un espacio vital y se convierte

10 Löw presta particular atención a las prácticas cotidianas del "aquí-sentirse-cómodo" y el "allí-sentirse-extraño" (Sich-hier-Wohlfühlen sund Sich-dort-Fremd fühlens).

11 Thrift sugiere que las ciudades deben ser pensadas a partir de una nueva política de los afectos, considerando por ejemplo los nudos emocionales, que estarían ligados a los cuerpos, al poder de las emociones; así como a la capacidad de afectar al otro y de ser afectado por el otro. 
en un espacio de tránsito, caracterizado por la insularidad (Löw 2001). Siendo un espacio "de tránsito", apela a formas de neutralidad espacial (Sennett 2002), limitando por ejemplo el uso espontáneo del espacio (Lefebvre 1972 y Araya 2013). Por esta razón, la discusión sobre el derecho a la ciudad ha emergido con particular fuerza en el debate académico (Lefebvre 1996; Harvey 2012; Attoh 2011 y Purcell 2002), considerándolo no solo como el derecho de acceder a los recursos de la ciudad sino a la transformación de la misma (Harvey 2012).

Por lo anterior, observar los discursos en los medios de comunicación sería una forma indirecta de incidir en los procesos de formación de opinión y toma de decisiones sobre el espacio público, tal como es propio de una "democracia deliberativa". Si los discursos en dichos medios (en este caso, la prensa escrita) presentan una práctica social de forma estereotipada o incompleta, o "criminalizan"a sus productores, la posibilidad degenerar cambios sustanciales hacia una democratización del espacio urbano se reduce. Sin embargo, cuando existe un debate sobre la legalidad o el derecho a la apropiación y uso del espacio, es posible esperar que los derechos de ciertas poblaciones sean visibilizados e incluso reconocidos. Una práctica social disidente, en vez de ser considerada "criminal", puede ser en realidad un acto político, incluso un acto de desobediencia civil (Habermas 1996, 383; Lefkowtiz 2007, 214), cuyo objetivo es la denuncia de una forma naturalizada de opresión o exclusión, o de una desigualdad estructural.

Los medios de comunicación, además de ser instituciones públicas o privadas que tienen sus propios objetivos políticos y económicos (Herman y Chomsky 1988), responden a criterios de noticiabilidad (Martini 2000; Hall et ál. 1980 y van Dijk 1988a) y a dinámicas de producción particulares (Ramonet 1998). Los $y$ las consumidores de dichos medios, en este caso "lectores", pueden — tal como indican Hall et ál. (1980) - optar por una lectura negociada o en oposición a los contenidos ofrecidos por el medio, que serían la lectura dominante o preferida. Al consumir informaciones mediáticas, los lectores tienen sus propias dinámicas (por ejemplo, Holsanova, Rahmy y Holmqvist 2003), sus propias posiciones de lectura y procesos cognitivos (D‘Haenens et. ál. 2004).

El periódico La Nación es considerado como un actor político y económico en esta discusión, dada su pertenencia al Grupo Nación, que incluye desde revistas hasta radioemisoras. Además, es posible pensar que La Nación es consumida por un cierto sector de la población costarricense - generalmente sectores medios $y$ altos - que son justamente los que más posibilidades (estructurales) tienen de involucrarse en procesos de formación de opinión y toma de decisiones. Los artículos de opinión analizados, por supuesto, son aprobados a lo interno del medio de comunicación, por dinámicas y criterios que no son evidentes para este investigador. En el caso de las noticias, los criterios de selección de fuentes y de otros factores de producción del texto periodístico son inferidos a partir de la revisión de literatura secundaria sobre prensa escrita (Martini 2000 y Ramonet 1998), pero no se excluye que otros criterios de noticiabilidad (o de intereses particulares de los medios de comunicación) hayan escapado el análisis aquí propuesto.

\section{PRÁCTICAS DEL GRAFFITI EN LA NACIÓN: 2001-2010}

GRAFFITI POLÍTICO COMO UNA FORMA IRREGULAR DE COMUNICACIÓN

Existe una diversidad de discursos asociados a distintas prácticas del graffiti en $\mathrm{La} \mathrm{Na}$ ción durante el periodo en estudio. En términos generales, es posible afirmar que los discursos tienden a ser más "tolerantes" y más abiertos a esta práctica hacia el final del periodo de estudio.

Primero, un gran número de artículo de noticias solamente menciona el graffiti en las notas al pie de fotografías, particularmente en relación con conflictos de corte social,político y económico, tanto a nivel nacional como internacional/global12. Este uso del "graffiti político"

\footnotetext{
12 Algunos de estos conflictos ilustrados a través de imágenes de graffiti político son: Las luchas entre defensores y oponentes a Hugo Chávez, el estado de la libertad de culto y religión en América Latina, la campaña electoral en Ecuador (Álvaro
} 
no fue abordado exhaustivamente en el estudio, debido a que las imágenes y las notas al pie fueron excluidas de la investigación. Sin embargo, es importante destacar que La Nación emplea frecuentemente este recurso de ilustración, aún cuando estos conflictos podrían ser representados a través de imágenes de lugares, de actores involucrados (autoridades, grupos de oposición, expertos, etc.), de diagramas, entre otros.

El "graffiti" es percibido como una forma política de comunicación, pero esta acción política es irregular o anómala. La política, en sentido estricto, tiende a ser practicada no a través de inscripciones no autorizadas en las superficies urbanas, sino a través de la recolección de firmas, de debate, de la protesta pacífica, del uso de lobby, del artículo de "opinión" en los medios, etc. Esta valoración política del graffiti es particularmente evidente en las noticias y artículos de opinión (incluyendo cartas de lectores) que fueron producidos durante el periodo de negociación del Tratado de Libre Comercio entre Estados Unidos, Centroamérica y República Dominicana (TLC) en 2007. Así, el graffiti puede ser político pero ensucia, es de mal gusto, de clase popular o baja:

Referéndum, ¿un hito histórico? Creo que no. ¿Ocurrencia para suplir la incapacidad local para tomar decisiones serias con la actitud requerida? Creo que sí. ¿La sepultura del futuro de la posibilidad de decidir por parte del que sabe o ha sido delegado para hacerlo? También. Es este el tiempo del eslogan simplón, el grafiti vulgar y de la "gradería de sol", esto es claro. Es la época del poder del minoritario, del imperio de la masa $y$, en general, de lokitsch (sic)" (Víquez 2007. Presbítero. Artículo de opinión).

Prácticas entristecedoras. El uso del grafiti, pintas y pegas son prácticas políticas que en los últimos procesos habían sido

Noboa-Rafael Correa, 2006), la expulsión del embajador de los Estados Unidos de Venezuela y Bolivia en 2007, la guerra en Irak, cumbres del G20, neo-Nazismo en Francia, entre otros. erradicadas; hoy, con gran tristeza, vemos que son revividas estas prácticas, reprochadas por todos, pues ensucian nuestros barrios, afectan el paisaje $y$, lo más preocupante, esconden en el anonimato a personas sin escrúpulos, que se aprovechan para ofender al contrario (Zavala 2007. Químico. Artículo de opinión).

Más allá del graffiti político, las firmas $\mathrm{u}$ otras formas del tagging son reducidas a la noción de vandalismo, relacionado con la búsqueda de prestigio social $y$ adrenalina. Estas prácticas de graffiti más territorial son consideradas como una amenaza a ideas de patrimonio, de una historia o identidad común. Las firmas, nombres, mensajes políticos que son escritos en edificios como el Colegio de Señoritas y el edificio de Correos de Costa Rica ${ }^{13}$, o en las (abandonadas) esculturas de la capital, son leídas como formas no estéticas que atentan contra el "cuerpo social". Dos ejemplos resumen esta idea del "graffiti" como "amenaza al patrimonio":

Con la mirada perdida en el infinito, monumentos, estatuas $y$ bustos ubicados en San José recuerdan algún fragmento de nuestra historia; no obstante, la gente $y$ las propias autoridades parecen haberlos olvidado, a pesar de que están muy cerca de las rutas más transitadas por los costarricenses. Esas obras se han convertido en una especie de indigentes de bronce, cemento y piedra.

La mayoría de monumentos josefinos da pena: unos están sucios y dañados por la contaminación, el paso del tiempo y las condiciones climáticas; otros están llenos de graffiti, basura y hasta chicles, $y$ una buena cantidad padece de todos los males anteriores (Díaz 2003. Periodista. Noticia).

13 Ver: "Colegio de Señoritas bajo agua y jabón" (La Nación, 18/02/2006) y "Edificio de Correos sufre 10 años de deterioro y abandono" (La Nación, 17/07/2006), ambas noticias por la periodista Doriam Díaz. 
Políticos, libertadores, artistas y ciudadanos ilustres inmortalizados en piedra, pasan los días sobre un pedestal sin que nadie se entere quiénes fueron. Algunos, han sido objeto de vandalismo $y$ recibieron como premio mutilaciones, graffitis o robos (Corella 2010. Periodista. Noticia).

Así, el graffiti es interpretado como el resultado de productores que son indiferentes al patrimonio y a la "historia común", sin considerar que estas inscripciones pueden ser también un rechazo a esta idea de identidad, herencia e idiosincrasia. La acción de escribir mi nombre en una superficie urbana, un "Marcela estuvo aquí"14, invita a la reflexión sociológica de si los espacios urbanos contemporáneos son formas solidificadas de exclusión de aquellos que son desconocidos, sin mérito, invisibles. ¿Por qué son solamente los "ciudadanos ilustres" quienes son inmortalizados en el espacio físico urbano? Esta idea de una ciudad que es edificada como un museo, que no admite modificación ni transformación espontánea, es cuestionada a través de nociones como el "derecho a la ciudad"15.

\section{GRAFFITI TERRITORIAL: DEL VANDALISMO CRIMINÓGENO A LAS EPIDEMIAS}

Al ser considerado como vandalismo, el "graffiti" es percibido a partir del ordenamiento jurídico-penal, orientado hacia la protección de la propiedad pública y privada. La práctica es generalmente reducida a sus características negativas, dejando de lado los efectos positivos que el "graffiti" puede aportar a la vida de los y las (jóvenes) productores: sentido de pertenencia, creatividad, perseverancia ante obstáculos, etc. (Lachmann 1988). La visión más extrema de esta oposición a las prácticas de graffiti está ligada al modelo de las Ventanas Rotas, con una

14 Ver: "Monumentos al abandono"(La Nación, 30/04/2001), por Doriam Díaz.

Sennett (2002: 98) enfatiza la existencia de grupos que se dedican a la preservación urbana de la ciudad como si fuera un "museo de edificios", en vez de ser un lugar para el desordenado "negocio" de la vida. serie de artículos de opinión que fueron publicados en el periódico La Nación:

El ejemplo de Nueva York. Con esta teoría podemos pensar en la sociedad como un edificio con muchas ventanas. $\mathrm{Si}$ ese edificio no está bien mantenido y se encuentra descuidado (paredes despintadas, manchadas o con grafitis, quizás hasta con algunas de sus ventanas rotas) es mucho más probable que el siguiente transeúnte que camine frente al edificio decida probar suerte, tome una piedra e intente con ella quebrar alguna de las ventanas que todavía se encuentren intactas (Jenkins 2006. Empresario. Artículo de opinión).

Muy pronto, más ventanas serán violentadas y la sensación de anarquía se contagia del edificio a los alrededores, transmitiendo la señal de que "todo es permitido". Según Wilson y Kelling, en una ciudad, problemas menores como grafitis, desorden público, robos y conductas agresivas, son el equivalente a "ventanas rotas", que a su vez son invitaciones a crímenes más serios. Esta es la teoría del crimen como epidemia. Su principio es que el crimen es contagioso, tanto como pueden serlo la música, la moda o una gripe (Rodríguez 2007. Lector. Artículo de opinión).

Esta lectura del orden que debe imponerse en el espacio público para la reducción de hechos criminales más serios se asocia no solamente a dicho modelo, sino a nuevas tendencias del urbanismo, desde espacios con сстv, pintura anti-climb y de ambientes diseñados contra la prevención del delito (сттеD) (Araya 2013). Sin embargo, debe enfatizarse de que a pesar de que estas estrategias contribuyen en cierta medida con la erradicación de la actividad criminal, las causas estructurales del delito $y$ la violencia no son atacadas con estos enfoques. Resulta particularmente cuestionable argumentar que la implementación directa de un modelo creado en los 70 en los Estados 
Unidos es la "solución" a los problemas de las sociedades latinoamericanas. En otras palabras, San José (en 2006-2007) no puede ser comparada con la Nueva York de los años 70, en la que dichas políticas fueron relativamente "exitosas".

En relación con el enfoque de las Ventanas Rotas, algunos autores van al extremo de comparar los grafiteros, así como, otros "delincuentes" con agentes de epidemias. Esta idea, implícita en el modelo a través del contagio de un espacio a otro, adopta un matiz más peligroso cuando se aplica a seres humanos. Al reducir tanto a los grafiteros como a los trabajadores sexuales, vendedores ambulantes, mendigos, etc., a una categoría subhumanaa través de metáforas que los representan como "gérmenes" o "virus", se niegan sus derechos básicos y resulta fácil justificar su eliminación (física y/o simbólica). El artículo "Zancudos con revólver" evidencia esta línea de argumentación:

El dengue y la delincuencia son idénticos. La primera vez al paciente le hierve la sangre, cuando lo pica un carterista que con 300 robos aún anda suelto. Tan pronto le pasan los 44 grados de fiebre decide inmunizarse; compra un arma. El siguiente ataque del mosquito-maleante será hemorrágico: correrá sangre. Los bichos evolucionan rápido y deciden que, además del candado chino, ya ocupan revólver, y mejor disparar primero. Epidemia mortal en las calles. La espiral continuaría hasta vernos actores en una película de vaqueros. El de gatillo más rápido gana el duelo $y$ vive para contar la historia.

Detener la epidemia. Hay que detener la epidemia, igual que el dengue, o acabará con nosotros. Eliminar criaderos y usar repelente. Si hay un mínimo brote, fumigar a conciencia.

En su libro "Tipping Point" o "punto de brote" el sociólogo Malcolm Gladwell analizó como epidemia de salud la ola delictiva en el metro de Nueva York. Era suicidio entrar en él. La Policía restauró luces y pintó vagones, pero además atacó delitos casi tontos: hacer grafitis y no pagar el tiquete. Cortar esas trivialidades eliminó también los atracos a mano armada y el miedo del público. Del estudio brotó un manantial de agua tibia: el ambiente sucio favorece crimen, pero uno ordenado y limpio genera seguridad. El que raya paredes hoy, asalta gente mañana (Monge 2008. Ingeniero. Artículo de opinión).

Esta visión de corte criminógena y epidemiológica del "graffiti" (territorial) resulta peligrosamente simplista $y$ reduccionista. "El que raya paredes hoy, asalta gente mañana" establece relaciones causales que solo pueden comprobarse a partir de datos e información científica, y no a partir de figuras retóricas o de estrategias argumentativas. La criminología crítica considera, por ejemplo, las técnicas de neutralización (Sykes y Matza 1957) que incidirían en ciertas formas de "criminalidad", al permitir una desconexión temporal de las nociones morales ${ }^{16}$. Si se considera el "apelar a lealtades mayores", es posible pensar que los productores que realizan graffiti político — por ejemplo, a favor del aborto o de la protección ambiental- pueden justificar sus acciones por esta causa mayor sin que esto signifique que vayan a convertirse en asaltantes $\mathrm{u}$ homicidas. Al entender las prácticas no-autorizadas del graffiti desde esta óptica, su "naturaleza" parece ser más la de acto de desobediencia civil que la de un "vandalismo" sin significado. Si estos individuos y/o grupos "voluntariamente" deciden "violar la ley", la idea de esta participación voluntaria también puede ser cuestionada, a partir de este "deber" de proteger causas mayores ${ }^{17}$.

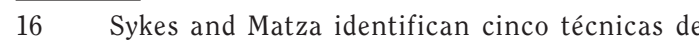
neutralización que permiten a los individuos la comisión de un "crimen": La negación de la responsabilidad, la negación del daño, la negación de la víctima, la condenación de los condenadores y el apelo a lealtades mayores.

17 Feinberg (1970: 170) se pregunta "si la acción de A es desencadenada por B, $y$ especialmente si es causada por la provocación intencional de B, ¿̇cómo es posible que se diga sin calificación que la propia 
Un artículo titulado "Precrimen", al parecer inspirado en la película Minority Report ${ }^{18}$, sugiere incluso luchar contra el graffiti "antes de que sea cometido", ignorando que nadie puede ser juzgado por un crimen que no cometió. Tal como señala Ferrell $(1993,142)^{19}$, el graffiti es presentado en estos casos en el peor escenario posible, comparándolo con otras formas más serias de criminalidad:

En el momento en que un ladronzuelo de esos se acerque demasiado a otro ser humano, ipaz!, el sistema de detección, acoso $y$ derribo, entra con prontitud $y$ detiene al sospechoso. Sin que este haya cometido ningún delito todavía. El nuevo equipo, también serviría para reconocer patrones de probable vandalismo contra monumentos y obras públicas. Mucho antes de que alguien del grupo de "pintas" saque el tarro de spray para el graffiti en alguna oscura pared, una patrulla se detiene frente a ellos $y .$.

Entiendo que las cámaras logran identificar rostros. Con suerte se podrá

acción de A es libre, informada y deliberada, que es un acto "completamente voluntario"?" [Traducción propia]. En este sentido, actos de desobediencia civil pueden ser el resultado del accionar involuntario e intencional de gobiernos locales, corporaciones, etc.

El "pre-crimen" es también el tema principal de la película Hollywoodense "Minority Report" (2004), protagonizada por Tom Cruise. En la historia, inspirada en una cuento corto escrito por Philip K. Dick en 1956, Cruise representa a un policía de la división de pre-crimen llamado John Anderton, quién es acusado del futuro crimen de un pedófilo (quién a su vez era supuestamente responsable del abuso y desaparición del hijo de Anderton). Las similitudes entre los argumentos del artículo y la película son evidentes.

19 En sus propias palabras: "Es difícil decir si estas tácticas son más ofensivas para las víctimas de violación o para los productores de graffiti; no es difícil ver que estas tácticas están diseñadas para ubicar el graffiti en el peor contexto posible." [Traducción propia]. En este caso particular, el graffiti es (discursivamente) comparado con abuso sexual a menores $y$ con asaltos. comenzar a detectar a hombres viejos que miran con lujuria a los chiquitos $y$ acusarles de futura pederastia. Por ahora solo pensemos si el uso de esa tecnología nos llevará a cuestionar si viola nuestro derecho a la libertad de movimiento o si, por el contrario, nos ayuda a no sufrir los embates del hampa (Leandro 2004. Columnista. Artículo de opinión).

Un último tema relacionado al "graffiti" como criminógeno se relaciona con el contexto histórico y geográfico del país: las maras en Centroamérica. El miedo de la expansión de estos grupos delictivos desde Guatemala, Honduras y El Salvador hacia ("la pacífica") Costa Rica se evidencia en una serie de artículos publicados tanto en la versión impresa como digital de La Nación ${ }^{20}$. Este enlace entre violencia $y$ graffiti también es visible en relación con "las barras de fútbol" (La Doce, La Ultra, etc.) ${ }^{21}$.Si bien, el graffiti es utilizado por las maras, por las barras de fútbol y por otros grupos que si están más relacionados con la reproducción de la violencia social que los productores de otras formas de graffiti (arte urbano, firmas, político, etc), la mera comparación de maras con las pandillas y barras de fútbol de Costa Rica resultaría ahistórica y descontextualizada.

\section{HIP-HOP,GRAFFITI, ARTE URBANO Y FORMAS DE INSTITUCIONALIZACIÓN}

Además de estos discursos negativos sobre las prácticas del graffiti, otros textos de La Nación reconocen el valor artístico, económico y social de las producciones. Generalmente, entendido como una manifestación de la cultura del hip-hop (junto con el rap, los DJs,

20 El "graffiti" y las maras aparecen ligados en diez artículos de noticias, nueve de ellos dedicados en forma exclusiva a este tema. Seis de estos artículos están disponibles solamente en la versión online de la Nación y por esta razón, fueron excluidos del análisis. La palabra "graffiti" aparece generalmente en las notas al pie de foto. Dichas imágenes muestran grupos de mareros posando frente de paredes cubiertas con graffiti y otras inscripciones.

21 Ver: "Una vergüenza nacional" (La Nación, 26/04/2004) opinión por Enrique Rosales. 
y el breakdancing), el graffiti en su versión más artística es valorado a partir de la institucionalización: la emergencia de zonas de tolerancia, de festivales, del teatro, la galería, de concursos escolares, entre otros.

El término de "zona de tolerancia" apunta a la creación de espacios que serían ofrecidos "libremente" a aquellos productores del graffiti que deseen expresarse. Tal como señalan Ferrell (1993) y Austin (2001), el riesgo de estas zonas de tolerancia es que una práctica que es regulada por sus propios (jóvenes) productores de forma espontánea, resulta regulada por autoridades e instituciones (generalmente, adultos). No solamente las formas de acceder estos espacios pueden ser controladas (a través de horarios y condiciones de uso), sino que se corre el riesgo de que los contenidos sean cooptados y controlados. Un ejemplo de esta tendencia se observa en una noticia sobre la Universidad de Costa Rica:

Las decenas de afiches publicitarios pegados en las paredes que anunciaban conciertos, grupos de ayuda social y hasta préstamos de dinero ya no se verán más en un tramo de las inmediaciones de la Universidad de Costa Rica (UCR), en San Pedro de Montes de Oca.

Ahora, ese espacio que cubre unos 200 metros al norte desde la Librería Universitaria, es ocupado por graffiti que fueron autorizados por los jerarcas de la casa de estudios superiores.

Si bien en algún momento se valoró la posibilidad de "otorgar" ese trayecto a los "graffiteros"(sic) que exhibían mensajes políticos, sociales y de otra índole, luego se cambió de opinión.

También se descartó la idea de repintar dichas paredes con el color institucional de la ucR y se solicitó la ayuda de cinco jóvenes para convertir esos 200 metros en un mural al aire libre (Díaz 2004. Periodista. Noticia).
En este ejemplo, el graffiti político es abiertamente considerado como "indeseado", con la subsecuente promoción de formas "más artísticas" de la práctica. Es interesante mencionar que estas producciones son consideradas como "graffiti" cuando parecen ser"murales", lo que coincide con los argumentos de productores de graffiti no-autorizado que rechazan considerarlas como parte de su cultura ${ }^{22}$.

La emergencia de estos murales demuestra además el valor social que se le atribuye al "graffiti" como medio de comunicación, como una forma de captar la población joven y crear conciencia sobre una causa social. En el periodo en estudio, esta tendencia es poco visible, aunque existen algunos ejemplos. Particularmente, se emplea el graffiti (arte urbano/mural) para crear consciencia sobre temas como las carreras ilegales de autos o la trata de personas:

Como parte de este proyecto, el domingo pasado se inauguró un grafiti alusivo a las carreras ilegales. El mural se pintó sobre una de las paredes de un puente de San Juan de Tibás (inmediaciones de la estación de Bomberos).

La pintura pretende educar $y$ advertir a los conductores, pues en un lado se refleja el concepto de vida, representado por un velocímetro que marca $80 \mathrm{~km} / \mathrm{h}$.

En otra parte del grafiti, se muestra la noche, asociada a la muerte. En esta pintura también se incluye un velocímetro, pero este marca los $180 \mathrm{~km} / \mathrm{h}$, una forma de conducción que evidencia la velocidad temeraria (Flores 2008. Periodista. Noticia).

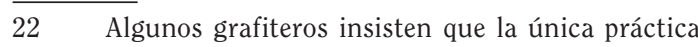
que debe considerarse como "graffiti" es aquella que es ilegal, contracultural e indomable. Esto se asocia, por ejemplo, a la apropiación no-autorizada de espacios públicos y privados, así como, a la obtención de los materiales para la producción del graffiti. Austin (2001:65) y Ferrell (1993:171-172) se refieren a esta tendencia de forma más detallada. 
El pasado 10 de febrero concluyó uno de esos talleres, en la comunidad de Rincón Grande de Pavas, con la pintura de un mural alusivo a la trata de personas en las paredes del "Polideportivo". Ayudados del pincel, de su creatividad y energía, los jóvenes empuñaron sus brochas e hicieron desaparecer parte de algunos grafitis, a ratos arte rebelde $y$ a ratos grito de desesperanza en medio del ocio infinito, de la droga o de la incertidumbre de quienes se expresan de esa forma. La gama de grises fue sustituida por todas las tonalidades del arco iris (de la Cruz 2008. Odontóloga. Artículo de opinión).

En estos dos textos se observa que en algunas ocasiones los términos mural/graffiti son considerados como sinónimos, mientras que en otros se presentan en oposición. Esta polisemia del término "graffiti" es interesante, debido a que por un lado la práctica es considerada como criminal $y$ delictiva, como una forma de vandalismo, de búsqueda irracional de estatus y de aceptación social; por otro lado, el "graffiti" es promovido y reconocido como arte e incluso fomentado $y / 0$ apoyado por instituciones.

Otra de estas contradicciones se relaciona con la idea anteriormente mencionada de que el "graffiti" es una amenaza al bien común, al patrimonio $y$ a la identidad costarricense (por el daño a monumentos y esculturas públicas). El "graffiti" que resulta nocivo y peligroso en un contexto es promovido incluso en escuelas y colegios, como parte integral de las manifestaciones de creatividad. Así, en 2008, se elimina la categoría de oratoria del Festival de la Creatividad del Ministerio de Educación Pública, pero se incluye el graffiti y se equipara (en cierto nivel) con otras manifestaciones autóctonas del país, como la marimba y los bailes folclóricos:

El Ministerio de Educación Pública (мер) eliminó el concurso de oratoria del Festival de la Creatividad.

Ese certamen, que ha sido tradicional y tenía una final nacional para primaria $y$ secundaria, quedó fuera porque el MEP alega que los estudiantes memorizan los discursos [...]

La funcionaria indicó que tienen otras 31 modalidades para el Festival de la Creatividad como cuento, poesía escrita, pintura, grafiti, historietas, bailes modernos, bandas de garaje, máscaras, papalote, cimarrona, bailes folclóricos, marimba, estudiantina, coro, solista vocal, afiche $y$ teatro (Villegas 2008. Periodista. Noticia).

Una posible explicación de esta contradicción es que el graffiti institucionalizado ("oficial" o de marca) es una forma diferencial "cooptada" que es promovida, justamente porque no es comparable con las formas no-autorizadas de la práctica (graffiti territorial o político). Estas diferencias deben ser observadas por la ciencia social, en el sentido de una necesaria de-construcción de los complejos fenómenos sociales llamados "culturas juveniles", de sus productos ("el" graffiti) y sus productores.

Sin embargo, el que "el" graffiti sea relativamente más aceptado en ciertas instituciones sociales no elimina el hecho de que la práctica o sus productores sean considerados como "inferiores". Un ejemplo claro es la respuesta a un artículo publicado sobre el trabajo del grafitero Alejandro Ramírez ${ }^{23}$, un artista consolidado tanto a nivel nacional como internacional. En 2004, este artículo de opinión compara este Alejandro Ramírez, grafitero, con un segundo Alejandro Ramírez, promesa del ajedrez costarricense:

Seamos realistas. Para pintar esos rótulos no se necesita más creatividad que la indispensable para escoger el color del spray ni más genio que la astucia para no dejarse ver de la Policía. (Porque pintar paredes públicas es ilegal; o ¿también en eso soy ingenuo?). Cierto es que de vez

23 Ver: "Alejandro Ramírez: Del Taki al TLC", reportaje por Astiasarán, C.columnista. (La Nación, $22 / 02 / 2004)$. 
en cuando contienen frases ingeniosas, como las que también salen en las cantinas y en las barras de pachucos. Pero, si todo eso se enaltece como arte (con sus consabidos parámetros de estética $y$ crítica, según se puede inferir del artículo), y si se presenta con gran despliegue en un prestigioso suplemento cultural, es que algo grave nos está pasando como sociedad.

¿Qué clase de trastrueque ha ocurrido en nuestro sistema de valores? ¿Acaso hay punto posible de comparación entre la disciplina, el esfuerzo y el genial raciocinio de un campeón de ajedrez, y la cuestionable conducta de un tocayo suyo a quien la mamá no le enseñó que uno no pinta las paredes? ¿Acaso es que ahora apreciamos más el actuar en la oscuridad y el hacer trampa que el demostrar auténtico ingenio y valía humana?

Tal vez se me podría replicar que soy un ignorante, $y$ que hace años que los graffiti se consideran un arte. Pero eso no haría sino corroborar mi punto. Debo anotar que ese mismo día, en el suplemento deportivo de La Nación, que no suelo leer, sí me encontré una buena crónica sobre las andanzas de Alejandro Ramírez, el otro, el de verdad (Vargas 2004. Lector. Artículo de opinión. Cursiva propia).

Como se ha mencionado al inicio de este artículo, el principal objetivo de la investigación era identificar estos diálogos y debates entre diversos actores sociales sobre las prácticas del graffiti $y$ sus productores. Si bien, el graffiti es presentado como positivo, mencionando su inclusión en productos culturales (como discos, moda, etc.) y destacando hasta su valor económico; la práctica aún es censurada, rechazada $y$ estigmatizada por diversos actores sociales, especialmente cuando es producida de forma "no-autorizada".
Un único artículo publicado en 2003 por la periodista Andrea Vásquez intenta presentar esta diversidad de fenómenos del graffiti, enfatizando de una manera balanceada las diferentes percepciones sobre el tema ${ }^{24}$. Este artículo es claramente una excepción, dado que durante el periodo analizado la mayoría de las noticias $y$ artículos de opinión aborda el graffiti como un tema tangencial, sin que este sea el tema central del texto.

\section{CONCLUSIONES GENERALES}

La complejidad y polisemia del término "graffiti" ha permitido identificar cinco discursos asociados a las prácticas y a sus productores:

MÉDICO / EPIDEMIOLÓGICO: HIGIENE Y POLÍTICAS DE SUCIEDAD. Presenta el graffiti como un agente contaminante, como amenaza al cuerpo social que se propaga de la periferia al centro o de las clases bajas a las clases altas. El "graffiti" responde a un impulso irracional de búsqueda de adrenalina y estatus. Los productores son reducidos a formas subhumanas, caracterizados como animales, gérmenes o virus. Un proceso de humanización es posible a través de la educación y la civilidad.

B) LEGAL: VANDALISMO, PATRIMONIO Y DEL ORDEN. A partir del ordenamiento jurídico, este enfoque entiende la práctica como amenaza contra la propiedad pública y privada, relacionado también con el simbolismo del patrimonio y la identidad común. Las y los productores son considerados como poco educados, sin sentido de pertenencia, indiferentes al orden legal. Se reconoce que la práctica tiene un valor político, pero es una forma irregular de la expresión política. Esto responde a la atribuida falta de espacios de inserción y de recreación de los productores.

C) CRIMINOGÉNICO: DE DROGAS A ROBOS. La práctica del "graffiti" es leída como una

$24 \quad$ Ver: "Las paredes tienen la palabra", reportaje por Andrea Vásquez, periodista (La Nación, 05/01/2003). 
introducción a formas severas de criminalidad, particularmente asociadas a pandillas criminales (drogas, robos, maras). Es una invitación a la transgresión, considerando la adrenalina que se genera de la práctica como una droga. Los productores no solamente atentan contra la sociedad en su conjunto sino contra sí mismos, exponiéndose al peligro (caídas, electrocución, brutalidad policial, etc.). Se les considera además como (potenciales) delincuentes, adictos, etc. Este discurso nace de enfoques ortodoxos como el modelo de las Ventanas Rotas.

D) USO SOCIAL: VALOR INDIVIDUAL Y SOCIAL ${ }^{25}$. Las prácticas del graffiti se entienden como útiles en relación con causas sociales o proyectos, orientadas hacia comunidades en riesgo (periféricas y empobrecidas). El graffiti (artístico) generaría un sentido de pertenencia, que contribuye a la autoestima. Los (jóvenes) productores son percibidos como "en riesgo", en necesidad de proyectos sociales que eviten su inserción en pandillas. Algunos de estos jóvenes usan la práctica del graffiti para convertirse en microempresarios, mejorando sus posibilidades de inserción en el mercado.

E) VALOR ARTÍSTICO: ARTE URBANO, CANVAS Y MUROS PRIVADOS. Es el "graffiti" más asociado al movimiento hip-hop, que contribuye a embellecer la ciudad y a mejorar el espacio físico. Este "graffiti" es similar al muralismo. Se evidencia una institucionalización a través de zonas de tolerancia, galerías, museos y del consumo privado (incluyendo sus usos para campañas de publicidad). Los productores son considerados jóvenes creativos, artistas (microempresarios) e incluso celebridades, asociadas a la cultural global del graffiti.

$25 \quad$ Este tipo de discurso es particularmente visible en el caso de Brasil. Sin embargo, en Costa Rica se observan algunos artículos que tienden hacia esta misma línea discursiva.
Estos cinco discursos no aparecen en forma aislada, sino que en muchas ocasiones se entrecruzan $y$ se hibridan, sin que esto signifique una necesaria contradicción en la "naturaleza" de la práctica. De hecho, esto evidencia la necesidad de investigar el graffiti en su diversidad, aproximando cada una de estas categorías por separado. El graffiti político y el arte urbano pueden compartir algunas características "esenciales" de lo que se entiende como "graffiti”, pero constituyen fenómenos separados.

En relación con los silencios o los temas no abordados por el medio de comunicación, $L a$ Nación publica pocas o casi ninguna referencia a las (auto)-denominadas víctimas del "graffiti”. Se recomienda que estudios posteriores se enfoquen en este grupo, para entender por qué se oponen a la práctica, cuáles consecuencias sufren, cuáles son sus percepciones de problemáticas similares al graffiti como "problema de calidad de vida". En este sentido, el smog y la prostitución pueden relacionarse ambos con el "graffiti", dependiendo del discurso que prefieran enfatizar las "víctimas"26.

La policía corresponde a otro de los temas que es poco abordado en los artículos analizados. Estos oficiales son los responsables de lidiar con los productores de formas no autorizadas de graffiti, por lo cual sería interesante entender cuáles son sus percepciones y su conocimiento del tema. Además, estudios sobre productores (grafiteros y grafiteras, artistas urbanos, movimientos sociales) pueden ayudar a destruir las relaciones causales simplistas que ligan las prácticas del graffiti con formas más severas de criminalidad.

Otro punto de interés es la investigación de los y las consumidores del graffiti, tanto en sus formas ilegales como en las institucionalizadas. Este consumo del graffiti puede asociarse con causas sociales e informativas, así como con

$26 \quad$ Ferrell(1993) señala que este tipo de retórica retrata a las "víctimas" de prácticas del graffiti como vulnerables y débiles, sin tener en cuenta que algunas de estas "víctimas" son en realidad miembros de clases media y alta, empresas, organizaciones o instituciones gubernamentales, quiénes además poseen mucho más poder y recursos que los productores de graffiti no-autorizado. 
la apreciación artística y de valor económico. El "graffiti" no sería en este sentido una forma exclusivamente juvenil, ya que adultos e incluso niños y niñas podrían ser consumidores de formas institucionalizadas de la práctica ( $y / 0$ incluso productores de las mismas). Una visión crítica de la juventud también abre la oportunidad para abordar aquellos sectores de esta población que se oponen a algunas prácticas del graffiti, lo que permitiría entender por qué algunos jóvenes se ofrecen como voluntarios para combatirlas, siendo agentes activos en campañas antigraffiti.

En resumen, las prácticas del graffiti en el contexto costarricense son abordadas en los artículos de opinión y de noticias del periódico La Nación en formas diversas, dependiendo del tipo de práctica y de la naturaleza del artículo. Los artículos de opinión destacaron particularmente el carácter criminógeno, epidemiológico $y$ de vandalismo de la práctica, con discursos que fueron perdiendo intensidad. En términos generales, el graffiti de corte más artístico y asociado al hip-hop, es valorado a través de su inserción en instituciones formales (gobiernos locales, universidades, museos), a través de zonas de tolerancia, de festivales y concursos. Estas formas institucionalizadas de la práctica siguen en competencia con las formas no autorizadas e informales del graffiti, lo que se evidencia también en la discusión del proyecto legislativo (nro. 17741) presentado ante el plenario para la regulación del "graffiti" 27 . El riesgo del éxito de estas formas institucionalizadas del graffiti es no solamente la cooptación de una práctica (juvenil) alternativa y/o de disidencia, sino la debilitación del debate público y el silenciamiento de causas sociales que no necesariamente alcanzan los medios de comunicación formales ( $y$ que son expresadas a través del graffiti político). Esta discusión académica debe considerar no solamente factores "estructurales" como el género, la clase, el grupo étnico, la orientación política e ideológica, sino formas de distinción más simbólica entre centro-periferia, high art-low art (de élite-popular), orden-desorden, entre otros.

$27 \quad$ Ver el proyecto "Ley de Regulación de Rayados, Pintas, Graffitis, Murales y similares, sobre Bienes Públicos y Privados".
BIBLIOGRAFÍA

LIBROS

Austin, Joe. 2001. Taking the train.How graffiti art became an urban crisis in New York City. New York: Columbia University Press.

Cohen, Stanley. 2002. Folk devils and moral panics. London: Routledge.

Feinberg, Joel. 1970. Doing and deserving. Essays in the theory of responsibility. New Jersey: Princeton University Press.

Ferrell, Jeff. 1993. Crimes of style. Urban graffiti and the politics of criminality. New York: Garland Publishing, Inc.

Ferrell, Jeff, Keith J. Hayward y Jock Young. 2008. Cultural criminology. London: SAGE Publications.

Goffman, Erving. 1963. Stigma. Notes on the management of spoiled identity. New York: Touchstone.

Habermas, Jürgen. 1990. Strukturwandel der öffentlichkeit. Untersuchungen zu einer kategorie der bürgerlichen gesellschaft 2. Frankfurt am Main: Suhrkamp,.

Habermas, Jürgen. 1996. Between facts and norms: contributions to a discourse theory of law and democracy. Trans. W. Rehg. Cambridge: Massachusetts Institute of Technology-mit Press.

Hall, Stuart, Dorothy Hobson, Andrew Lowe y Paul Willis. 1980. Culture, media, language.working papers in cultural studies, 1972-1979. Gran Bretaña: Hutchinson y Centre for Contemporary Cultural Studies University of Birmingham.

Harvey, David. 2012. Rebel cities. From the right to the city to the urban revolution. London: Verso.

Harvey, David. 2001. Spaces of capital. Towards a critical geography. Edinburgh: Edinburgh University Press.

Herman, Edward y Noam Chomsky. 1988. Manufacturing consent. The political economy of the mass media. New York: Pantheon Books.

Kozak, Claudia. 2004. Contra la pared. Sobre graffitis, pintadas y otras intervenciones urbanas. Buenos Aires: Libros del Rojas. 
Läpple, Dieter. 1992. "Essayüber den Raum. Für ein gesellschaftliches Raumkonzept". Stadt und Raum. Hartmut Häußermann. Pfaffenweiler: Centaurus-Verl.-Ges,.

Lefebvre, Henri. 1972. La revolución urbana. Madrid: Alianza Editorial.

Lefebvre, Henri. 1996. Writings on cities. Trad. Eleonore Koffman y Elizabeth Lebas. Oxford: Blackwell.

Löw, Martina 2001. Raumsoziologie. Frankfurt am Main: Suhrkamp.

Löw, Martina. 2010. Soziologie der Städte. Frankfurt am Main: Suhrkamp.

Macassi, Sandro. 2001. Culturas juveniles, medios y ciudadanía. Lima: Asociación de Comunicadores Sociales Calandria.

Manco, Tristan, Caleb Neelon y Lost Art. 2005. Graffiti Brasil. London: Thames \& Hudson Ltd.

Martín-Barbero, Jesús, Guillermo Sunkel, Martha Nubia, Ninca Pacari y José Manuel Valenzuela. 2005. América Latina, otras visiones desde la cultura. Bogotá: Convenio Andrés Bello.

Martini, Stella. 2000. Periodismo, noticia y noticiabilidad. Bogotá: Grupo Editorial Norma.

Musgrove, Frank. 1964. Youth and the social order. London: Routledge and Kegan Paul.

Ramonet, Ignacio. 1998. La tiranía de la comunicación. Madrid: Debate.

Reguillo, Rossana. 2000. Emergencia de culturas juveniles. Estrategias del desencanto. Bogotá: Grupo Editorial Norma.

Sennett, Richard. 2002. The fall of the public man. London: Penguin Books,.

Sennett, Richard. 1990. The conscience of the eye: the design and social life of cities. New York: Alfred A. Knopf.

Silva, Armando. 1986. Una ciudad imaginada. graffiti lexpresión urbana. Bogotá: Universidad Nacional de Colombia.

Tonkiss, Frank. 2004. "Analysing text and speech: content and discourse analysis". En Researching society and culture, editado por Clive Seale, 367-382. London: Sage.
VanDijk, Teun. 1988a. News analysis. Case studies of international and national news in the press. New Jersey: Lawrence Erlbaum Associates, Inc., Publishers. Acceso el 19 de junio de 2012. http:// www.discourses.org/OldBooks.

Van Dijk, Teun. 1988b. News as discourse. New Jersey: Lawrence Erlbaum Associates, Inc., Publishers. Acceso el 19 de junio de 2012. http://www.discourses.org/ OldBooks.

\section{PUBLICACIONES PERIÓDICAS}

Altheide, David. 1997. "The news media, the problem frame and the problem of fear". The sociological quarterly 4 , n. ${ }^{\circ} 38$ : 647668.

Araya López, Alexander. 2013. "Ciudades espontáneas: seguridad y espacio público en América Latina”. Geopolítica(s). Revista de Estudios sobre Espacio y Poder2, n. ${ }^{\circ}$ : 281-304.

Astiasarán, Clara Concepción. 2004. "Alejandro Ramírez: del Taki al tcc”. La Nación. 22 de febrero. Acceso el 06 de abril de 2013. http://wvw.nacion.com/ancora/2004/ febrero/22/ancora5.html.

Attoh, Kafui A. 2011. "What kind of right is the right to the city?". .Progress in Human Geography 58, n. ${ }^{\circ} 35:$ 669-685.

Avritzer, Leonardo y Sérgio Costa. 2004. "Teoria crítica, democracia e esfera pública: Concepções e usos na America Latina". Dados 478, n. ${ }^{\circ}$ : 703-728.

Bell, Allan. 2011. "Re-construction Babel: discourse analysis, hermeneutics and the interpretive arc". Discourse Studie 13: 519-568.

Corella V., Randall. 2010. "¿Y vos quién fuiste?”. La Nación. 17 de octubre. Acceso el 06 de abril de 2013. http://wfnode01.nacion. com/2010-10-17/Proa/NotaPrincipal/ Proa2522232.aspx.

Cruz, Tania. 2008. "Instantáneas sobre el graffiti mexicano: historias, voces $y$ experiencias juveniles". Última década 29: 137-157.

de la Cruz, Yalena. 2008. "Sueños, esperanza y libertad”. La Nación. 8 de marzo. 
Acceso el 06 de abril de 2013. http:// wvw.nacion.com/ln_ee/2008/marzo/08/ opinion1454261.html.

D'Haenens, Leen, Nicholas Jankowski y Ard Heuvelman. 2004. "News in online and print newspapers: differences in reader consumption and recall". New Media Society 6: 363-382.

Díaz, Doriam. 2001. "Monumentos al abandono". La Nación. 30 de enero. Acceso el 06 de abril de 2013. http://wvw. nacion.com/viva/2001/abril/30/cull.html.

Díaz, Doriam. 2003. "Indigentes de bronce". La Nación. 20 de octubre. Acceso el 06 de abril de 2013. http://wvw.nacion.com/ viva/2003/octubre/20/portada.html.

Díaz, Doriam. 2006. "Colegio de Señoritas bajo agua y jabón". La Nación. 18 de febrero. Acceso el 06 de abril de 2013. http:// wvw.nacion.com/ln_ee/2006/febrero/18/ aldea 0. html.

Díaz, Doriam. 2006. "Edificio de Correos sufre 10 años de deterioro y abandono". La Nación. 17 de julio. Acceso el 06 de abril de 2013. http://wvw.nacion.com/ ln_ee/2006/julio/17/aldea0.html.

Díaz, Luis Eduardo. 2004. "Murales de 'arte callejero"”. La Nación. 12 de diciembre. Acceso el 06 de abril de 2013. http://wvw. nacion.com/ln_ee/2004/diciembre/12/ pais 0. html.

Duschinsky, Robbie. 2013. "The politics of purity: when, actually, is dirt matter out of place?" Thesis Eleven.119 8, n. ${ }^{\circ} 1$ : 63-77.

Ferrell, Jeff. 1999. "Cultural criminology". Annual Review of Sociology 25: 395-418.

Flores, Ana Yancy. 2008. "Estudiantes contra 'piques' callejeros". La Nación. 14 de agosto. Acceso el 06 de abril de 2013. http://wvw.nacion.com/ cajadecambios/2008/agosto/14/ cajadecambios1653007.html.

Fraser, Nancy. 1990. "Rethinking the public sphere: a contribution to the critique of actually existing democracy". Social Text 25/26. Durham. Duke University Press: 56-80.

Goold, Benjamin, Ian Loader y Angélica Thumala. 2010. "Consuming security? tools for a sociology of security consumption". Theoretical Criminology 18, n. ${ }^{\circ}$ 14: 3-30.

Guidry, John y Mark Sawyer. 2003. "Contentious pluralism: the public sphere and democracy". Perspectives on Politics 28, n. ${ }^{\circ}$ 1: 273-289.

Holsanova, Jana; Henrik Rahm y Kenneth Holmqvist. 2006. "Entry points and reading paths in newspaper spreads: comparing a semiotic analysis with eye-tracking measurements". Visual Communication 5: 65-93.

Jenkins, Mauricio. 2006. "(In)seguridad ciudadana y ventanas rotas". La Nación. 26 de febrero. Acceso el 06 de abril de 2013. http://wvw.nacion.com/ln ee/2006/febrero/26/opinion7.html.

Kaytal, Neal Kumar. 2002. "Architecture as Crime Control". The Yale Law Journal 5, n. ${ }^{\circ} 111:$ 1039-1139.

Kelling, George L. y James Wilson. 1982. "Broken windows: the police and neighborhood safety". Atlantic Monthly 3, n. 249: 29-38.

Lachmann, Richard. 1998. "Graffiti as Career and Ideology". American Journal of Sociology 2, n..$^{\circ}$ 4: 229-250.

Leandro, Mauricio. 2004. "En el futuro: precrimen”. La Nación. 01 de marzo. Acceso el 06 de abril de 2013. http://wvw. nacion.com/viva/2004/marzo/01/var2. html.

Lefkowitz, David. 2007. "On a moral right to civil disobedience". Ethics 2, n. ${ }^{\circ} 117: 202$ 233.

Ley, David y Roman Cybriwsky. 1974 "Urban graffiti as territorial markers". Annals of the Association of American Geographers 4, n. ${ }^{\circ} 64:$ 491-505.

McRobbie, Angela, y Sara L. Thornton. 1995. "Rethinking 'moral panic' for multimediated social worlds". The British Journal of Sociology 4, n. ${ }^{\circ} 46$ : 559-574.

Monge Conejo, César. 2008. "Zancudos con revolver". La Nación. 12 de mayo. Acceso el 06 de abril de 2013. http:// www.nacion.com/opinion/Zancudosrevolver_0_975902428.html. 
Purcell, Mark. 2004. "Excavating lefebvre: the right to the city and its urban politics of the inhabitant". GeoJournal 58: 99-108.

Rodríguez, José Pablo. 2007. "Ventanas rotas". La Nación. 28 de enero. Acceso el 06 de abril de 2013. http://www.nacion.com/ opinion/Ventanas-rotas_0_881911854. html.

Rosales Álvarez, Enrique. 2004. "Una vergüenza nacional". La Nación. 26 de abril. Acceso el 06 de abril de 2013. http://wvw.nacion. com/ln_ee/2004/abril/26/opinion7.html.

Sampson, Robert y Stephen Raudenbush. 2004. "Seeing disorder: neighborhood stigma and the social construction of "broken windows"”. Social Psychology Quarterly 4, n. ${ }^{\circ} 67: 319-342$.

Schlecht, Neil. 1995. "Resistance and appropiation in Brazil: how the media and the official culture institutionalized São Paulo's grafite". Studies in Latin American Popular Culture 14: 37-67.

Stinchcombe, Arthur. 1963. "Institutions of privacy in the determination of police administrative practice".American Journal of Sociology 2, n. ${ }^{\circ}$ 69: 150-160.

Sykes, Gresham y David Matza. 1957. "Techniques of neutralization: a theory of delinquency". American Sociological Review 6, n. 22: 664-670.

Thrift, Nigel. 2005. "But malice aforethought: cities and the natural history of hatred." Transactions of the Institute of British Geographers, New Series 2 n. ${ }^{\circ} 30$ : 133150.

Vargas, Carlos Alonso. 2004. "¿El ajedrecista o el graffitero?". La Nación. 01 de marzo. Acceso el 06 de abril de 2013. http:// wvw.nacion.com/ln_ee/2004/marzo/01/ opinion7.html.

Vázquez R., Andrea. 2013. "Las paredes tienen la palabra". La Nación. 05 de enero de 2003. Acceso el 06 de abril. http://wvw. nacion.com/dominical/2003/enero/05/ dominical0.html.

Villegas S., Jairo. 2008. "MEP eliminó oratoria de Festival de la Creatividad". La Nación. 02 de setiembre. Acceso el 06 de abril de 2013. http://www.nacion.com/
nacional/MEP-elimino-oratoria-FestivalCreatividad_0_998500259.html.

Víquez, Mauricio. 2007. "Referéndum: ¿hito histórico?". La Nación. 16 de mayo. Acceso el 06 de abril de 2013. http://www. nacion.com/opinion/Referendumhitohistorico_0_903509647.html.

Welsh, Brandon, y David Farrington. 2003. "Effects of closed-circuit television on crime". Annals of the American Academy of Political and Social Science 587: 110-135.

Yar, Majid. 2012. "Crime, media and the will-to-representation: reconsidering relationships in the new media age". Crime Media Culture 8, n. ${ }^{\circ}$ 3: 245-260.

Zahm, Diane 2007. "Using crime prevention through environmental design in problem-solving". U.S. Department of Justice: Problem-Oriented Guides for Police Series 8. Acceso el 19 de junio de 2012. http://www.cops.usdoj.gov/ Publications/e0807391.pdf.

Zavala Ortega, Walter. 2007. "La vida continúa”. La Nación. 21 de setiempbre. Acceso el 06 de abril de 2013. http:// www.nacion.com/opinion/foros/vidacontinua_0_929107274.html.

TESIS

Araya López, Alexander. 2014. "Public spaces, stigmatization and media discourses of graffiti practices in Latin American press: dynamics of symbolic exclusion and inclusion of urban youth". Tesis doctoral en Sociología. Freie Universität.

Rodríguez, Marvin. 2014. "Graffiti artístico en Costa Rica: Una mirada sociológica". Tesis de Licenciatura en Sociología. Universidad de Costa Rica.

Villegas, Marialina. 2009. "Apropiación del espacio público urbano a través del graffiti: los casos del Edificio Saprissa y Barrio La California en San José, Costa Rica". Tesis de Licenciatura en Antropología. Universidad de Costa Rica.

Fecha de ingreso: 05/08/2014 Fecha de aprobación: 30/01/2015 